Article

\title{
High Light Acclimation Mechanisms Deficient in a PsbS-Knockout Arabidopsis Mutant
}

\author{
Young Nam Yang ${ }^{1}$, Thi Thuy Linh Le ${ }^{2}$, Ji-Hye Hwang ${ }^{2}$, Ismayil S. Zulfugarov 1,3(D, Eun-Ha Kim ${ }^{1}$, \\ Hyun Uk Kim ${ }^{4}{ }^{\mathbb{O}}$, Jong-Seong Jeon ${ }^{5} \mathbb{C}^{2}$, Dong-Hee Lee ${ }^{2}$ and Choon-Hwan Lee ${ }^{1,6, *}$
}

1 Department of Integrated Biological Science, Department of Molecular Biology, Pusan National University, Busan 46241, Korea; longhoo@naver.com (Y.N.Y.); iszulfugarov@pusan.ac.kr (I.S.Z.); eunhada@korea.kr (E.-H.K.)

2 Graduate Department of Life and Pharmaceutical Sciences, Center for Cell Signaling \& Drug Discovery Research, Ewha Womans University, Seoul 03760, Korea; lethithuylinh13@gmail.com (T.T.L.L.); hwangjh0012@naver.com (J.-H.H.); lee@ewha.ac.kr (D.-H.L.)

3 Institute of Molecular Biology and Biotechnology, Azerbaijan National Academy of Sciences, 11 Izzat Nabiyev Avenue, Baku AZ 1073, Azerbaijan

4 Department of Bioindustry and Bioresource Engineering, Plant Engineering Research Institute, Sejong University, Seoul 05006, Korea; hukim64@sejong.ac.kr

5 Graduate School of Biotechnology, Crop Biotech Institute, Kyung Hee University, Yongin 17104, Korea; jjeon@khu.ac.kr

6 New Mexico Consortium, Los Alamos, NM 87544, USA

* Correspondence: chlee@pusan.ac.kr

\section{check for}

updates

Citation: Yang, Y.N.; Le, T.T.L.;

Hwang, J.-H.; Zulfugarov, I.S.; Kim,

E.-H.; Kim, H.U.; Jeon, J.-S.; Lee,

D.-H.; Lee, C.-H. High Light

Acclimation Mechanisms Deficient in

a PsbS-Knockout Arabidopsis

Mutant. Int. J. Mol. Sci. 2022, 23, 2695.

https://doi.org/10.3390/

ijms23052695

Academic Editors: Yong Li and

Richard T. Sayre

Received: 22 January 2022

Accepted: 26 February 2022

Published: 28 February 2022

Publisher's Note: MDPI stays neutral with regard to jurisdictional claims in published maps and institutional affiliations.

Copyright: (C) 2022 by the authors. Licensee MDPI, Basel, Switzerland. This article is an open access article distributed under the terms and conditions of the Creative Commons Attribution (CC BY) license (https:// creativecommons.org/licenses/by/ $4.0 /)$

\begin{abstract}
The photosystem II PsbS protein of thylakoid membranes is responsible for regulating the energy-dependent, non-photochemical quenching of excess chlorophyll excited states as a shortterm mechanism for protection against high light (HL) stress. However, the role of PsbS protein in long-term HL acclimation processes remains poorly understood. Here we investigate the role of PsbS protein during long-term HL acclimation processes in wild-type (WT) and npq4-1 mutants of Arabidopsis which lack the PsbS protein. During long-term HL illumination, photosystem II photochemical efficiency initially dropped, followed by a recovery of electron transport and photochemical quenching ( $\mathrm{qL}$ ) in WT, but not in npq4-1 mutants. In addition, we observed a reduction in lightharvesting antenna size during HL treatment that ceased after HL treatment in WT, but not in npq4-1 mutants. When plants were adapted to HL, more reactive oxygen species (ROS) were accumulated in npq4-1 mutants compared to WT. Gene expression studies indicated that npq4-1 mutants failed to express genes involved in plastoquinone biosynthesis. These results suggest that the PsbS protein regulates recovery processes such as electron transport and qL during long-term HL acclimation by maintaining plastoquinone biosynthetic gene expression and enhancing ROS homeostasis.
\end{abstract}

Keywords: arabidopsis; gene expression; high light acclimation; plastoquinone synthesis; PsbS

\section{Introduction}

Being sessile organisms, plants have developed sophisticated acclimation mechanisms to cope with unpredictable challenges in their environment. While light is essential for photosynthesis, growth, and reproduction, the exposure of plants to high light (HL) that exceeds their capacity to dissipate the excessive light energy may cause a range of HL stress responses. Light availability can be highly variable and unpredictable in nature. When plants are exposed to excessive HL, the over-excitation of the photosynthetic apparatus triggers short-term protection mechanisms as well as several long-term acclimation processes. As an important short-term HL protection mechanism, non-photochemical quenching (NPQ) dissipates excess excitation energy as heat to reduce oxidative damage [1,2]. Rapidly relaxing qE-type energy-dependent quenching is a fast and major component of NPQ that relies on the development of a trans-thylakoid proton gradient $(\Delta \mathrm{pH})$, the accumulation 
of zeaxanthin involved in the xanthophyll cycle, and the presence of a PsbS subunit of photosystem (PS) II [3-7]. A qE-deficient mutant, npq4-1 lacking the PsbS protein of PSII was reported in Arabidopsis [7]. The role of the PsbS protein in $\mathrm{qE}$ generation has now been confirmed in a number of vascular plants including rice PsbS knockout mutants $[4,5]$ and Populus PsbS RNAi lines [8]. HL stress ultimately causes the generation of multiple reactive oxygen species (ROS), including hydrogen peroxide $\left(\mathrm{H}_{2} \mathrm{O}_{2}\right)$, superoxide anion radicals (hereafter superoxide) $\left(\mathrm{O}_{2}^{-}\right)$, and singlet oxygen $\left({ }^{1} \mathrm{O}_{2}\right)$ that can cause damage and act as signaling molecules involved in regulating development and pathogen defense responses [9] The long-term protection mechanisms to HL stress or HL acclimation processes include dynamic changes in gene expression involved in hormone biosynthesis, signaling, and photosynthesis, the anthocyanin biosynthesis pathway genes [10], the composition, and the structure of the thylakoid membrane [11-14], accumulation of antioxidant metabolites and scavenging enzymes [15,16], and reducing LHCII antenna size [17-19].

In PsbS knockout rice mutants, a high level of superoxide is accumulated under photo-inhibitory illumination. This may be due to changes in the redox state of the plastoquinone (PQ) pool [5]. Significantly, the redox state of the PQ pool controls many aspects of photosynthesis. Furthermore, higher PQ pool-reduction states were detected in Arabidopsis and rice plants lacking the PsbS protein $[5,20]$. However, the underlying mechanisms of the control of the PQ pool redox state in $p s b S$ mutants are largely unknown. Plastoquinone-9 (PQ-9) is a photosynthetic electron carrier in chloroplast thylakoid membranes, carrying electrons from PSII to the cytochrome b6/f complex [21]. Oxidized PQ also acts as a ROS scavenger in plant leaves, playing a central photoprotective role [22]. When Arabidopsis plants were exposed to long-term HL, the amount of plastoquinone rapidly decreased, followed by a progressive recovery during the acclimation phase [2], indicating a critical role for PQ in HL stress responses.

In this study, we investigated the role of PsbS protein during the HL acclimation processes in Arabidopsis. We compared several HL acclimation processes in WT with those in npq4-1 mutants. To understand the underlying molecular mechanisms involved in the PsbS-dependent HL acclimation process, we carried out gene expression analyses using gene set enrichment analysis (GSEA) systems [23]. GSEA evaluates microarray data at the level of gene sets. This gene set analysis is not useful for discovering new genes, but it is useful in discovering gene sets that have the same or related biological functions [24]. A co-expressed gene set is defined as a cluster of genes that have similar expression patterns under various conditions [23]. From GSEA and qRT-PCR analyses, we observed that the expression of genes involved in PQ-9 biosynthesis was substantially reduced in npq4-1 mutants during long-term HL illumination resulting in a reduction in the PQ pool size. From these results, we suggest that $\mathrm{PQ}$ biosynthesis is one of the acclimation processes induced under HL stress. We propose that the induction of many acclimation processes including PQ biosynthesis is reduced due to the over-accumulation of ROS.

\section{Results}

To monitor the changes in PSII photochemical efficiency (Fv/Fm) of plant leaves under HL illumination, leaves of Arabidopsis WT and npq4-1 mutants grown at low (70 $\mu \mathrm{mol}$ photons $\mathrm{m}^{-2} \mathrm{~s}^{-1}$ ) photosynthetic photon flux density (PPFD) and were harvested in the middle of the day followed by exposure to HL at $700 \mu$ mol photons $\mathrm{m}^{-2} \mathrm{~s}^{-1}$ for up to five days. The temperature at the surface of leaves was set to $15^{\circ} \mathrm{C}$ to accelerate the effect of HL stress. During the first $9 \mathrm{~h}$ of HL illumination, PSII photoinactivation was rapid, as shown by the rapid drop of Fv /Fm from 0.8 to 0.37 in the WT and 0.8 to 0.17 in the npq4-1 mutants, respectively (Figure 1A). Afterward, PSII photochemical efficiency slowly increased in the WT plants, as indicated by a progressive increase in $\mathrm{Fv} / \mathrm{Fm}$, reaching a value greater than 0.7 after $5 \mathrm{~d}$. However, PSII photochemical efficiency in the npq4-1 mutants dropped to 0.16 and failed to recover after five days (Figure 1A). During HL illumination ( $5 \mathrm{~d}$ ) changes in leaf color were observed indicating anthocyanin accumulation in the WT leaves, but in the npq4-1 mutants, the changes in leaf color were less obvious, and photobleaching was 
observed in older leaves (Figure 1B). Figure 1C shows the gradual changes in Fv/Fm during HL illumination for $3 \mathrm{~d}$ in whole leaves in the intact WT and the npq4-1 mutant plants. Similar to detached leaves, the Fv/Fm of the intact leaves of WT dropped substantially until $24 \mathrm{~h}$ but recovered after HL treatment, but in the case of the npq4-1 mutants, leaves that had substantially reduced $\mathrm{Fv} / \mathrm{Fm}$ ratios did not recover. These results indicated that the WT plants were being damaged before 24-h HL treatment, but after 24-h treatment, the WT plants were entering the acclimation process. However, in the case of the npq4-1 mutants, damaged plants could not recover and photobleaching occurred.

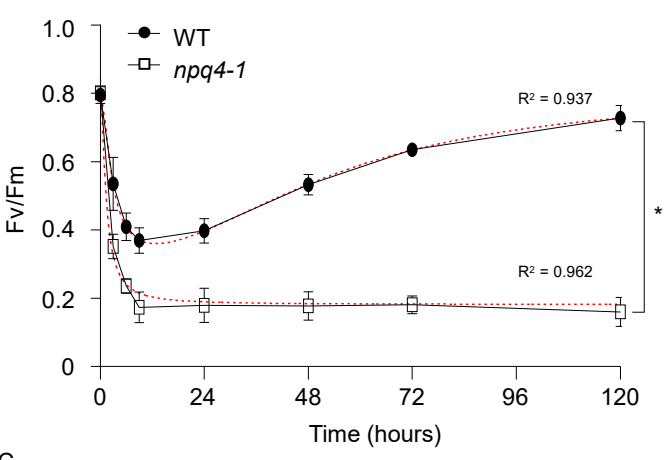

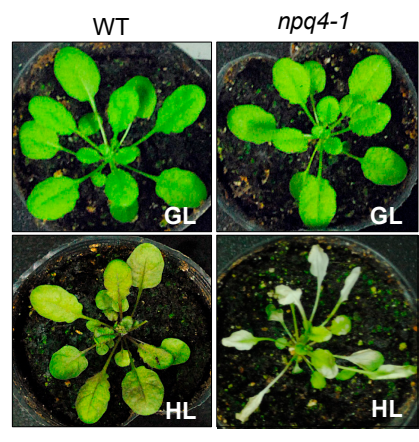

C

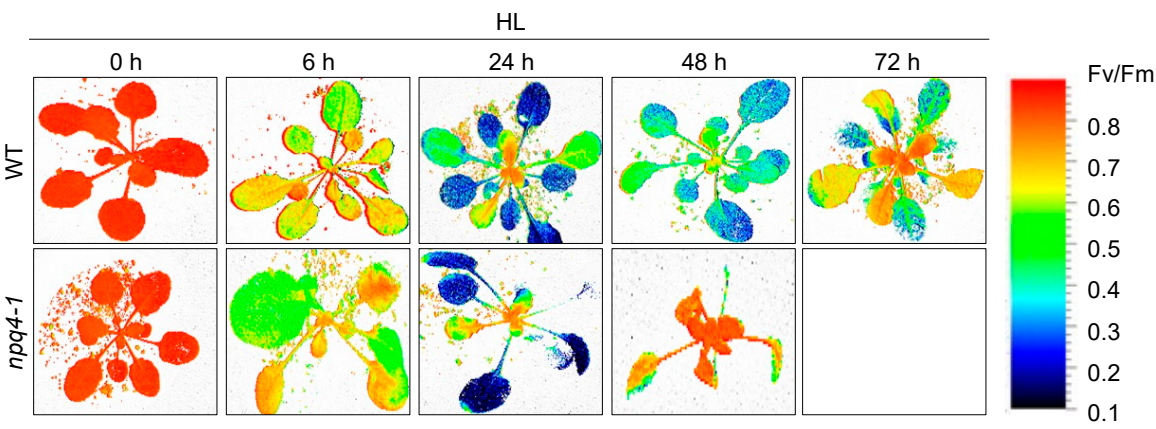

Figure 1. Changes in Fv/Fm and visible phenotypes of WT and npq4-1 mutants during high light illumination. (A) Changes in the photochemical efficiency of PSII (Fv/Fm) during high light (HL) treatment for up to 5 days. The means and standard errors $( \pm \mathrm{SE})$ from three to five replicates are shown. Regression line plotted as red dashed line estimated via nonlinear least square regression. $\mathrm{R}^{2}$ denotes the regression coefficient. Significance differences of fitted curves are indicated by asterisks ( $\left.{ }^{*} p<0.05\right)$ compared to the WT as determined by unpaired Student's $t$ test; (B) The visible phenotype of the WT and npq4-1 mutants grown under growth light (GL) at $70 \mu \mathrm{mol}$ photons $\mathrm{m}^{-2} \mathrm{~s}^{-1}$ for 4 weeks after transfer to HL at $700 \mu \mathrm{mol}$ photons $\mathrm{m}^{-2} \mathrm{~s}^{-1}$ for $3 \mathrm{~d}$; (C) Chlorophyll fluorescence images for $\mathrm{Fv} / \mathrm{Fm}$. The bar on the right side is the color scale for $\mathrm{Fv} / \mathrm{Fm}$.

To address the role of NPQ in the HL acclimation process, we measured the NPQ light response curves in WT and npq4-1 plants during HL treatments. After HL illumination for $9 \mathrm{~h}$, the NPQ values in WT became higher than in non-treated control leaves, but the NPQ values dropped significantly following HL illumination for $24 \mathrm{~h}$ and further decreased after $48 \mathrm{~h}$ HL treatment (Figure 2A). As shown in Figure 2B, the degree of NPQ development in npq4-1 plants exposed to variable illumination intensities was largely impaired during HL illumination presumably due to the loss of the PsbS protein [3]. These results show that the PsbS protein plays an important role in HL stress amelioration during short-term HL treatments, but that PsbS is not an essential factor during long-term HL treatments. 

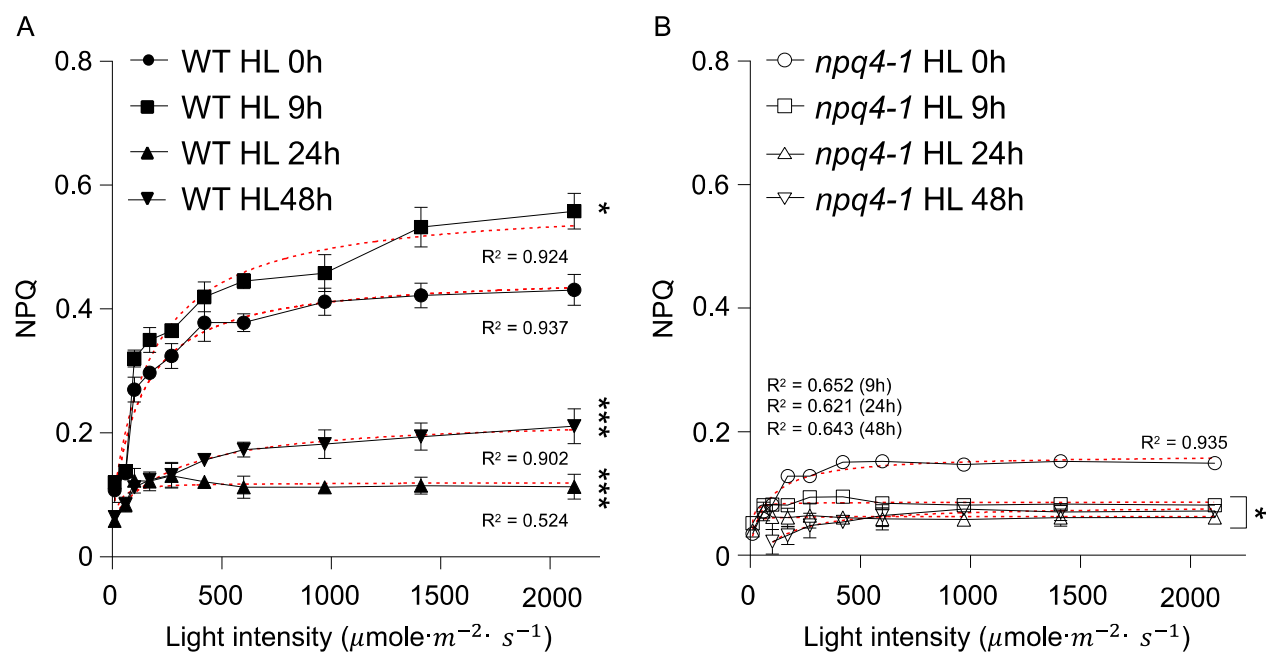

Figure 2. Light response curves for non-photochemical quenching in wild-type and npq4-1 mutants during high light illumination. Leaves of 4-weeks-old seedlings grown in a growth chamber were treated with high light (HL) at $700 \mu \mathrm{mol}$ photons $\mathrm{m}^{-2} \mathrm{~s}^{-1}$ for $0,9,24$, or $48 \mathrm{~h}$ and dark-adapted for $10 \mathrm{~min}$ before the measurement of non-photochemical quenching (NPQ). Each photosynthetically active irradiance of $0,70,110,180,250,400,550,900,1400$, or $2200 \mu \mathrm{mol}$ photons $\mathrm{m}^{-2} \mathrm{~s}^{-1}$ was applied for $10 \mathrm{~min}$ for the measurement in (A) WT; and (B) npq4-1 mutant leaves. NPQ was calculated as described in Section 4. Each point represents the mean of at least four experiments (SD indicated by the bar). Regression line plotted as red dashed line estimated via nonlinear least square regression. $\mathrm{R}^{2}$ denotes the regression coefficient. Significance differences of fitted curves are indicated by asterisks $\left({ }^{*} p<0.05\right.$; *** $p<0.001)$ compared to the $0 \mathrm{~h}$ as determined by one-way ANOVA with Fisher's LSD test.

The major component of NPQ, energy-dependent quenching (qE) includes the accumulation of the xanthophyll cycle pigment zeaxanthin associated with the development of the $\mathrm{pH}$ gradient across the thylakoid membrane and the PsbS protein $[7,25]$. We compared the rise in kinetics of de-epoxidation state of the xanthophyll cycle pigments in WT and npq4-1 mutant plants. As shown in Figure 3A, there was almost no noticeable difference in the de-epoxidation rise kinetics between WT and npq4-1 mutants. This is not surprising since xanthophyll cycle activities in npq4-1 mutants are reported to be fully functional $[7,26]$. Additionally, there was no change in the size of the xanthophyll pool during the HL treatment for three days and no noticeable difference between WT and npq4-1 (Figure 3B).

Because $\mathrm{qE}$ develops during photosynthetic electron transport, light intensity dependent changes in electron transport rates (ETR) were compared between WT and npq4-1 mutants (Figure 4). In non-HL-treated plants, the light intensity dependent ETR curve in WT plants was very similar to npq4-1 mutants. After HL illumination for $9 \mathrm{~h}$, the ETR curves in both WT and npq4-1 mutants were severely reduced. However, reduced ETRs were partially recovered during acclimation for $24 \mathrm{~h}$ and further after $48 \mathrm{~h}$ treatment, but no ETR recovery was observed in $n p q 4-1$ mutants.

A chlorophyll fluorescence parameter, $\mathrm{qL}$, was measured to access the fraction of open PSII centers, newly derived from the lake model [27]. As shown in Figure 5, there was no difference in qL values between WT and npq4-1 mutants before HL illumination. However, the $\mathrm{qL}$ values decreased rapidly during the HL treatment period for $9 \mathrm{~h}$ in WT plants. Interestingly, qL decreased even further in npq4-1 mutants than in WT plants. As observed here, under the photo-inhibitory condition, the fraction of open PSII centers, qL, decreases which reflects the rapid changes in the redox level of the PQ pool. After HL illumination for $24 \mathrm{~h}$, WT plants entered into an acclimation phase associated with the gradual recovery of qL values, but qL values in npq4-1 plants did not recover at all. 

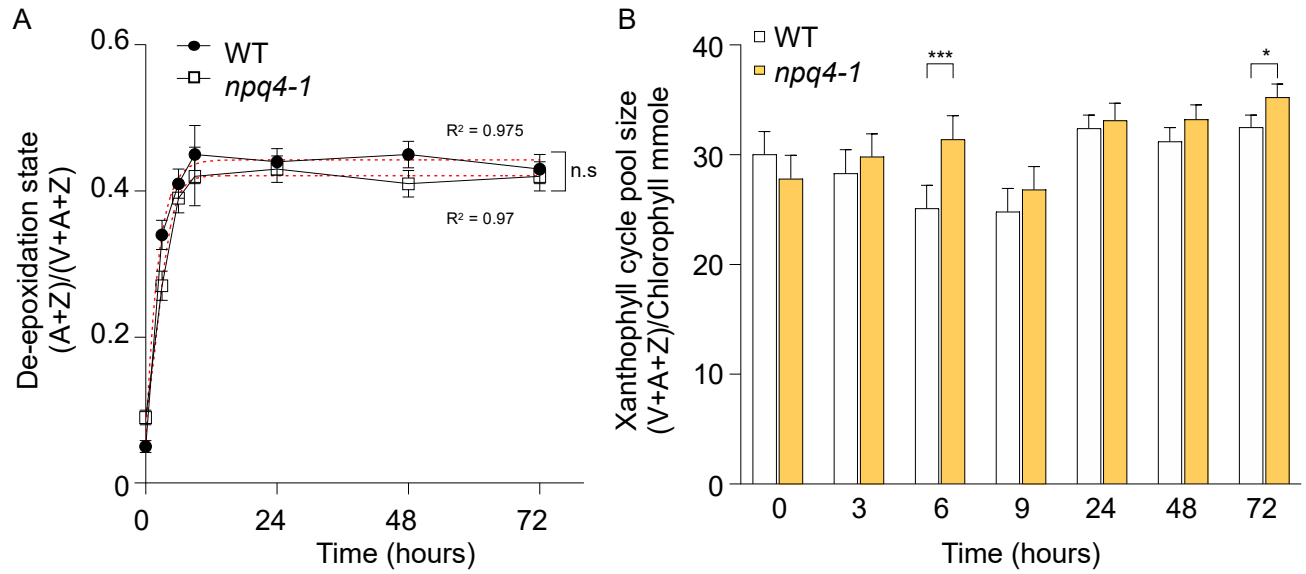

Figure 3. Changes in xanthophyll cycle pigment de-epoxidation state and pigment pool size in wild-type and npq4-1 mutants during high light illumination. (A) Xanthophyll cycle pigment deepoxidation state is calculated as $(\mathrm{A}+\mathrm{Z}) /(\mathrm{V}+\mathrm{A}+\mathrm{Z})$, where $\mathrm{V}$ is violaxanthin, $\mathrm{A}$ is antheraxanthin, and $Z$ is zeaxanthin. Data are the means \pm SE $(n=3)$. Regression line plotted as red dashed line estimated via nonlinear least square regression. $\mathrm{R}^{2}$ denotes the regression coefficient. Significance differences of fitted curves are indicated by asterisks $\left({ }^{*} p<0.05\right.$; $\left.{ }^{* * *} p<0.001\right)$ compared to the WT as determined by unpaired Student's $t$ test; (B) Total xanthophyll cycle pigments in WT and npq4-1 mutants during HL treatments. Pool size was calculated by total chlorophyll $a+b$. Pigment was extracted by $80 \%$ acetone and analyzed by HPLC using absorbance at $460 \mathrm{~nm}$. Significance differences are indicated by asterisks $\left({ }^{*} p<0.05 ;{ }^{* * *} p<0.001\right)$ compared to the WT as determined by one-way ANOVA with Fisher's LSD test.
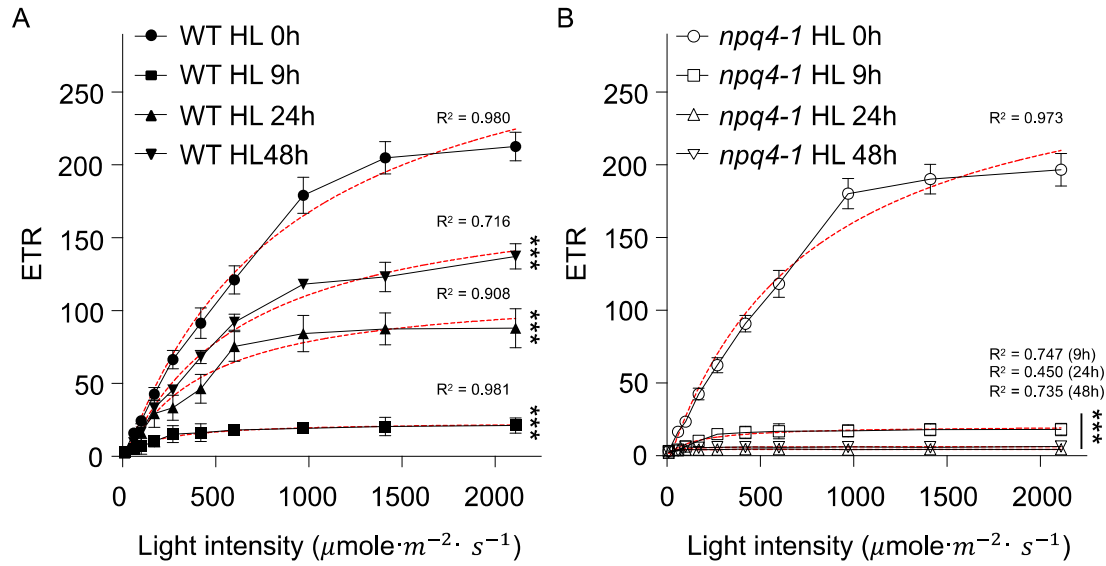

Figure 4. Light response curves for electron transport rate in wild-type and npq4-1 mutants during high light illumination. Leaves of 4-weeks-old seedlings grown in a growth chamber were treated with high light (HL) at $700 \mu \mathrm{mol}$ photons $\mathrm{m}^{-2} \mathrm{~s}^{-1}$ for $0,9,24$, or $48 \mathrm{~h}$ and dark-adapted for $10 \mathrm{~min}$ before the measurement of electron transport rate. Each photosynthetically active irradiance of 0 , $70,110,180,250,400,550,900,1400$, or $2200 \mu \mathrm{mol}$ photons $\mathrm{m}^{-2} \mathrm{~s}^{-1}$ was applied for $10 \mathrm{~min}$ for the measurement in (A) WT; and (B) npq4-1 mutant leaves. The electron transport rate was calculated as described in Section 4. Each point represents the mean of at least four experiments (SD indicated by the bar). Regression line plotted as red dashed line estimated via nonlinear least square regression. $\mathrm{R}^{2}$ denotes the regression coefficient. Significance differences of fitted curves are indicated by asterisks (*** $p<0.001)$ compared to the $0 \mathrm{~h}$ as determined by one-way ANOVA with Fisher's LSD test. 


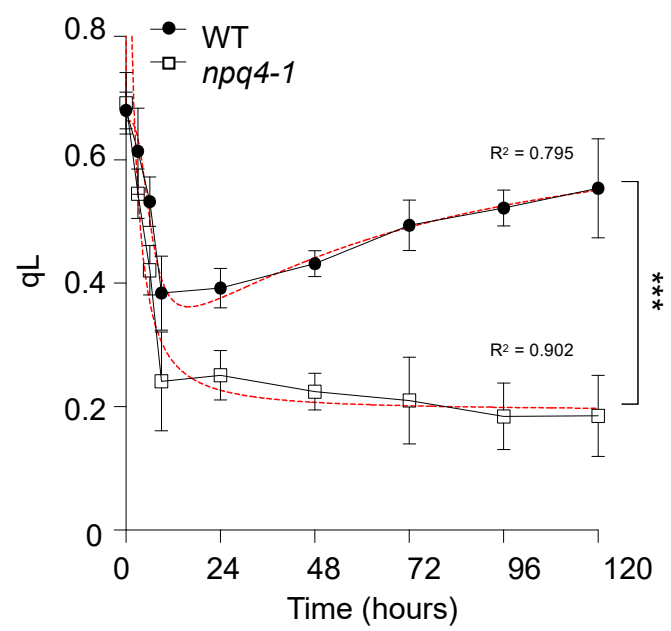

Figure 5. Changes in the fraction of open PSII centers, qL, in wild-type and npq4-1 mutants during high light illumination. Leaves of 4-weeks-old seedlings grown in a growth chamber were treated with high light (HL) at $700 \mu \mathrm{mol}$ photons $\mathrm{m}^{-2} \mathrm{~s}^{-1}$ and dark-adapted for $10 \mathrm{~min}$ before the measurement of $\mathrm{qL}$. The parameter $\mathrm{qL}$ was calculated as described in Section 4. Each point represents the mean of at least four experiments (SD indicated by the bar). Regression line plotted as red dashed line estimated via nonlinear least square regression. $\mathrm{R}^{2}$ denotes the regression coefficient. Significance differences of fitted curves are indicated by asterisks $\left({ }^{* * *} p<0.001\right)$ compared to the WT as determined by unpaired Student's $t$ test.

Exposure to excessive light in both WT and npq4-1 mutants resulted in the production of ROS $[5,20]$. The accumulation of superoxide was visualized by histochemical staining of the whole plant of Arabidopsis with nitroblue tetrazolium (NBT) (Figure 6A-top panels). In low-light-grown control plants, no noticeable difference was observed between WT and npq4-1 mutants. However, in the case of HL-treated plants, npq4-1 plants stained darker than WT plants, suggesting that more superoxide was accumulated in npq4-1 mutants compared to WT. Because superoxide is rapidly dismutated to more stable hydrogen peroxide by SOD [28], hydrogen peroxide production was measured by histochemical staining with 3, 3'-diaminobenzidine (DAB) (Figure 6A-bottom panels). DAB test results were very similar to those from the superoxide accumulation test, suggesting that more hydrogen peroxide was accumulated in npq4-1 mutants compared to WT following HL stress. Singlet oxygen is also a photosynthesis byproduct that is mainly formed from PSII under HL conditions, and which may damage the photosynthetic apparatus [29]. Therefore, singlet oxygen production was also measured in WT and npq4-1 leaves using the singlet oxygen sensor green (SOSG) [30,31]. In HL-untreated control leaves, the kinetics for increased SOSG fluorescence emission induced by photo-inhibitory illumination in npq4-1 plants was similar to the kinetics in WT. However, in the case of HL-treated leaves, singlet oxygen production increased in both WT and npq4-1 leaves but was greater in $n p q 4-1$ leaves than in WT leaves (Figure 6B). 
A

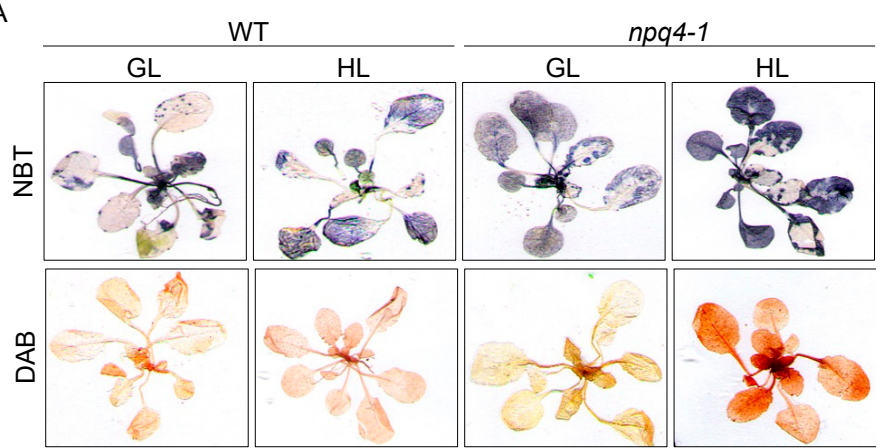

B

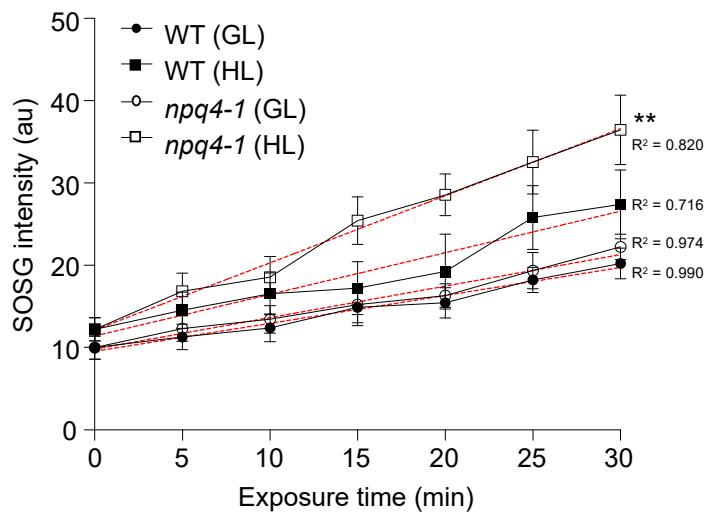

Figure 6. ROS production in wild-type and npq4-1 mutants under growth light and high light illumination. (A) Production of superoxide anion radicals and hydrogen peroxide was detected by histochemical staining with NBT (top panel) and DAB (bottom panel) in wild-type (WT) and npq4-1 leaves, respectively. Leaves infiltrated with $6 \mathrm{mM} \mathrm{NBT}$ or $5 \mathrm{mM}$ DAB solution by immersion for $12 \mathrm{~h}$ in darkness were treated with growth light (GL) at $70 \mu \mathrm{mol}$ photons $\mathrm{m}^{-2} \mathrm{~s}^{-1}$ or high light (HL) at $700 \mu \mathrm{mol}$ photons $\mathrm{m}^{-2} \mathrm{~s}^{-1}$ for $2 \mathrm{~h}$. The leaves were decolorized by immersing them in $70 \%$ ethanol. Experiments were repeated 4-6 times and representative images are shown; (B) Detection of singlet oxygen in leaves, as monitored by the increase in SOSG fluorescence emission at $530 \mathrm{~nm}$. Leaf segments were vacuum infiltrated with $200 \mu \mathrm{M}$ SOSG solution before being illuminated for $30 \mathrm{~min}$ with GL at $70 \mu \mathrm{mol}$ photons $\mathrm{m}^{-2} \mathrm{~s}^{-1}$ or with $\mathrm{HL}$ at $700 \mu \mathrm{mol}$ photons $\mathrm{m}^{-2} \mathrm{~s}^{-1}$. Regression line plotted as red dashed line estimated via nonlinear least square regression. $\mathrm{R}^{2}$ denotes the regression coefficient. Significance differences of fitted curves are indicated by asterisks $(* * p<0.01)$ compared to the $0 \mathrm{~h}$ as determined by one-way ANOVA with Fisher's LSD test.

Changes in the chlorophyll $\mathrm{a} / \mathrm{b}$ ratio as a result of acclimation to a fluctuating light environment have been used as a measure of the changes in the relative LHCII contents in chloroplasts of vascular plants and microalgae [32-34]. When Arabidopsis WT plants were transferred to HL conditions (700 $\mu \mathrm{mol}$ photons $\left.\mathrm{m}^{-2} \mathrm{~s}^{-1}\right)$, the chlorophyll a/b ratio increased from 2.8 to 3.4 (Figure 7A), which is in accordance with previous results [33,35-37]. However, under the same conditions, npq4-1 mutants showed a more rapid increase in the chlorophyll a/b ratio from 2.8 to 3.2 at the beginning of HL treatment, but during the acclimation phase, chlorophyll $\mathrm{a} / \mathrm{b}$ ratios dropped and the total chlorophyll amount decreased faster than WT (Figure 7B). The total chlorophyll content (per $g$ fresh weight) in both plants decreased during the HL treatment for $3 \mathrm{~d}$, however, the loss of Chl in npq4-1 mutants was faster than in WT plants (Figure 7B). 

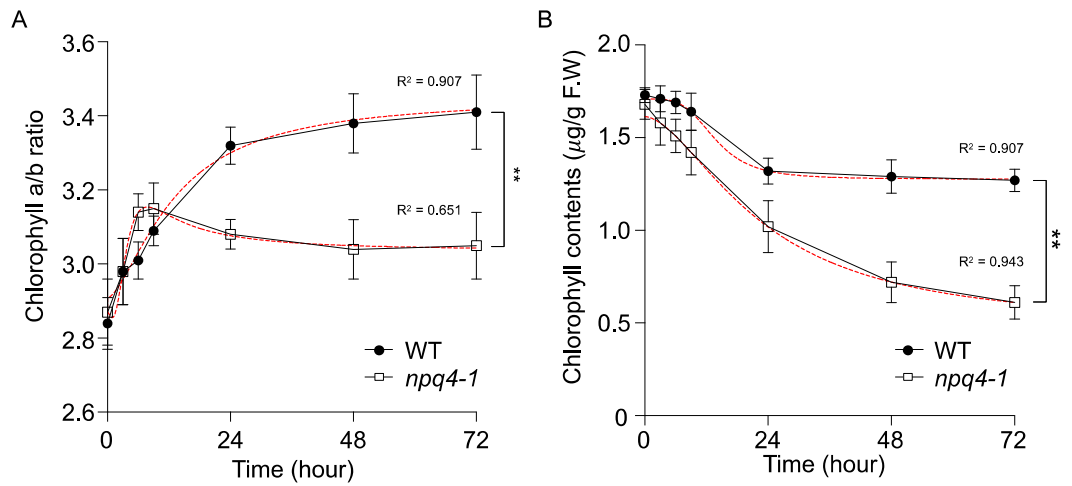

Figure 7. Change in chlorophyll $\mathrm{a} / \mathrm{b}$ ratio and chlorophyll contents in wild-type and npq4-1 mutants during high light illumination. (A) Chlorophyll a/b ratio reflects LHCII proportion of photosystem during the HL treatment; (B) Chlorophyll contents during HL treatment were expressed as $\mu \mathrm{g}(\mathrm{g} \mathrm{FW})^{-1}$. Fresh weight was determined after HL treatment. Regression line plotted as red dashed line estimated via nonlinear least square regression. $\mathrm{R}^{2}$ denotes the regression coefficient. Significance differences of fitted curves are indicated by asterisks $\left({ }^{* *} p<0.01\right)$ compared to the WT as determined by unpaired Student's $t$ test.

To capture any differences in gene expression during HL acclimation, we analyzed mRNA pool sizes for various genes in WT and npq4-1 mutants after HL treatments for either $3 \mathrm{~h}$ or $24 \mathrm{~h}$ by microarray analysis. Microarray results were analyzed by the Gene Set Enrichment Analysis (GSEA) program, and the results were visualized on a co-expression terrain map with 27 co-expressed gene sets (Figure 8A, here, each of 27 gene sets was named according to its position in the panel shown in the left-top corner). Since gene sets that were relatively closely related in their expression patterns converged into one ridge, the numbers of gene sets on the terrain map did not always correlate to the numbers of enriched gene sets in each analysis. We used pairwise comparisons (e.g., $0 \mathrm{~h}$ of WT-HL versus $3,24 \mathrm{~h}$ of WT-HL or $0,3,24 \mathrm{~h}$ of $n p q 4-1-\mathrm{HL}$ ) to identify differentially expressed genes at each time point in WT and the npq4-1 mutants (as shown in five panels in Figure 8A). In each panel, gene sets positively enriched in each treatment are visualized by red square dots, and conversely gene sets negatively enriched are represented by blue square dots. For the 27 co-expressed gene sets, the color code for each gene set is tabulated in Figure 8B. The short-term HL treatment for $3 \mathrm{~h}$ lead to the identification of six co-expressed gene sets that were positively enriched in WT. Only three of the gene sets remained positively enriched after $\mathrm{HL}$ treatment for $24 \mathrm{~h}$. In npq4-1 mutants treated with HL, the enriched gene sets were different from those in WT except for the F16 gene set, which was also positively enriched in HL-treated mutants for $24 \mathrm{~h}$. Two gene sets, G14 and L09, were interesting for us in that these gene sets were positively enriched in both WT plants treated with HL for $3 \mathrm{~h}$ and $24 \mathrm{~h}$, but not in HL-treated npq4-1 mutants. The lists of genes are tabulated in Supplemental Table S1 for G14 and in Supplemental Table S2 for L09.

The genes encoding Solanesyl Diphosphate Synthase 2 (SPS2) and a tocopherol cyclase (Vitamin Deficient 1; VTE1), involved in PQ and tocopherol biosynthesis, were notable in the G14 gene set. Both enzymes are involved in PQ biosynthesis and knock-out mutants have been shown to be sensitive to high light [2,38]. Recently, SPS-over-expression plants have been shown to accumulate higher amounts of PQ during HL acclimation and show tolerance to high light [2]. To gain a better understanding of how gene expression is regulated by HL and to confirm microarray data, we analyzed the expression of $\mathrm{PQ}$ biosynthesis genes in WT and npq4-1 mutants during HL stress by qPCR. As previously reported [2], known HL-induced PQ biosynthesis genes (e.g., SPS1, SPS2, VTE1 and VTE3) were highly induced during HL stress in WT, but the induction of PQ biosynthesis genes was very slow in $n p q 4-1$ compared with that in WT (Figure 9). These expression patterns confirm the results obtained from the microarray analysis. 
A
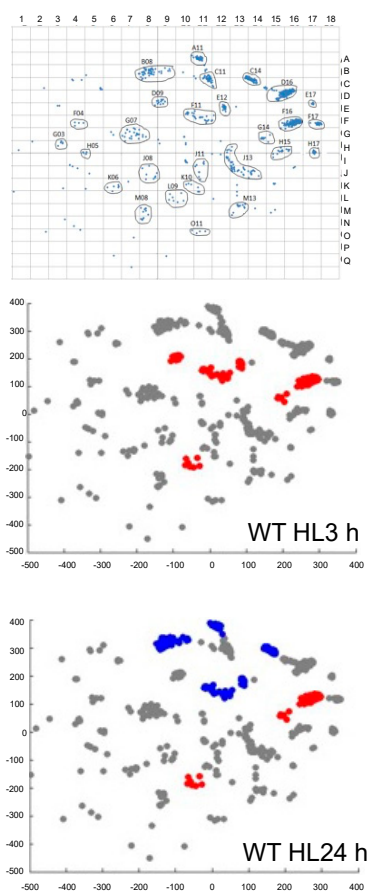
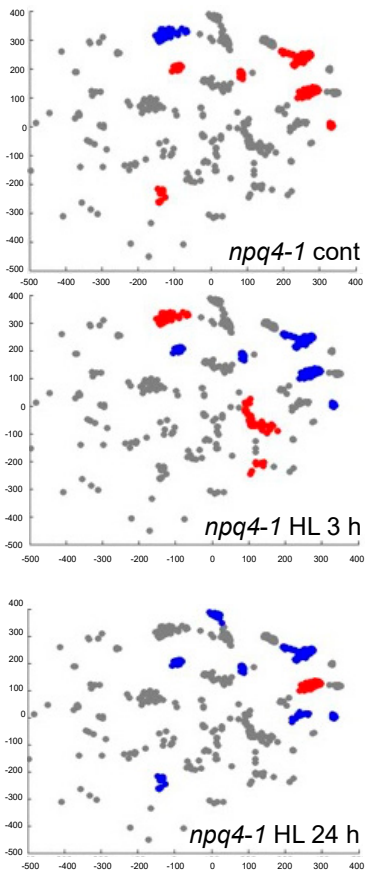

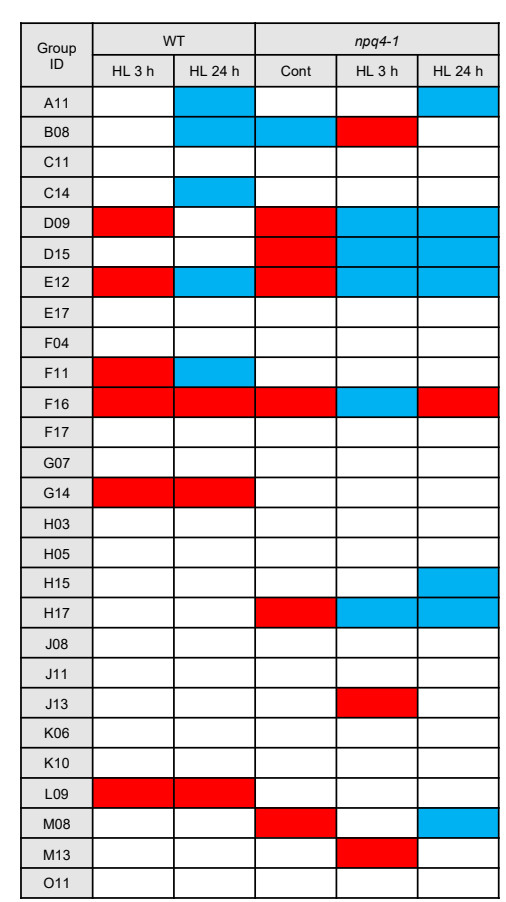

Figure 8. The co-expressed gene sets enriched in wild-type and npq4-1 mutants during high light illumination. (A) The position on the co-expression terrain map of differentially co-expressed gene sets is represented. Gene sets positively enriched for each treatment are represented in red color and conversely, gene sets negatively enriched are represented in blue color. The $\mathrm{x}, \mathrm{y}$ coordinates of the gene sets on the co-expression terrain map correspond to the names of the gene sets; (B) Gene sets were visualized by heat map. WT, wild-type; MT, mutant; HL, high light.
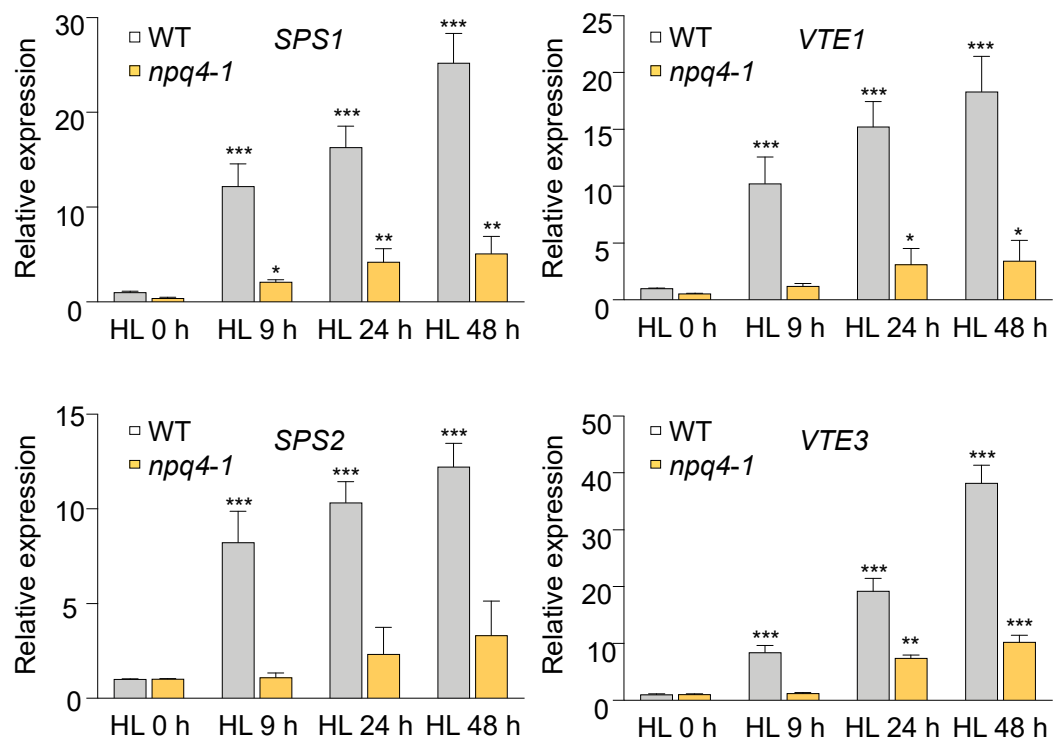

Figure 9. RT-qPCR analysis of PQ synthesis gene expression in WT and npq4-1 plants in response to HL. Four-week-old Col- 0 and npq4-1 plants were treated with PPFD of $700 \mu \mathrm{mol}$ photons $\mathrm{m}^{-2} \mathrm{~s}^{-1}$ at $19^{\circ} \mathrm{C}$ on the surface of adaxial side of the leaf. Values represent means $\pm \mathrm{SD}(n=3$ biological replicates). Significance differences are indicated by asterisks $\left({ }^{*} p<0.05,{ }^{* *} p<0.01,{ }^{* * *} p<0.001\right)$ compared to the HL $0 \mathrm{~h}$ WT as determined by one-way ANOVA with Fisher's LSD test. 


\section{Discussion}

In order for plants to survive in constantly changing and/or stressful environments they must be able to alter their metabolism to reduce and manage potentially stress-related damage. Light is one of the fastest-changing abiotic stress factors. When light levels exceed the capacity of photosynthesis, the excess absorbed energy can lead to the inactivation of the reaction centers (RCs) largely due to the formation of reactive oxygen species (ROS) which leads to a reduction in electron transport efficiency and photosynthesis as a whole-the phenomenon known as photo-oxidation or photo-inhibition [39,40].

Both photochemical mechanisms and non-photochemical protection mechanisms have been shown to reduce damage to PSI and PSII. The former mechanisms lead to enhanced electron sink strengths to prevent the over-reduction of electron carriers in the photosynthetic electron transfer chain, including the activation of key Calvin-Benson cycle enzymes, which can be easily monitored by measuring ETR. The latter mechanisms involve the dissipation of excess energy absorbed by the photosystems as heat, which can be easily monitored by measuring NPQ. Under photo-inhibitory conditions, some parts of the photosynthetic apparatus cannot be adequately protected by short-term protection mechanisms and are continuously damaged. The damage, however, can be repaired rapidly to continue photosynthetic activities. In addition to short term HL stress protection systems, longer-term repair systems are also engaged to maintain photosynthetic efficiency. In this study, we show that PsbS-deficient Arabidopsis npq4-1 mutants could not adapt to HL stress as well as WT plants as shown by their reduced ability to recover PSII photochemical efficiency or Fv/Fm relative to WT plants (Figure 1). To understand the molecular basis for this reduced repair capacity in the PsbS-deficient mutant, we compared known, as well as less well known, characterized protection or acclimation mechanisms in WT and npq4-1 mutants.

Acclimation to high light stress also involves physiological and molecular alterations of the photosynthetic membrane, such as an increased chlorophyll a/b ratio, reduced lightharvesting antenna size, increased anthocyanin content, higher content of the cytochrome $\mathrm{b}_{6} \mathrm{f}$ complex and fewer antenna complexes LHCII and CP24 [19,33,41-45]. In this study, as a sign of high light stress acclimation, we observed that chlorophyll degradation stopped after $\mathrm{HL}$ illumination for $24 \mathrm{~h}$ in WT, but in npq4-1 mutants chlorophyll degradation continued to decrease for $5 \mathrm{~d}$ (Figure 7B). Together with chlorophyll degradation, the LHCII levels in both plants were reduced as shown in Figure 7A [45,46]. In addition, the reduction in PSII antenna size slowed down after $24 \mathrm{~h}$ of HL illumination. This result suggests that the reduction of antenna size is an important HL acclimation mechanism, but the PsbS deficient mutants failed to acclimate by reducing antenna size.

Long-term HL acclimation processes also include the accumulation of antioxidant metabolites including chlorophyll intermediates and anthocyanin and the activation of ROS scavenging enzymes [16,47]. As shown in Figure 6, when plants were grown in HL for $2 \mathrm{~h}$, the amounts of three different ROS species were lower in WT compared with the npq4-1 mutants, suggesting that WT can acclimate well to reduce ROS production, but not npq4-1 mutants.

Processes related to non-photochemical ways of protection did not show any sign of recovery after HL illumination for $48 \mathrm{~h}$ in WT leaves (Figure 2A). In addition, there were no significant differences between WT and npq4-1 mutants in the changes both in the pool size and in the de-epoxidation state of the xanthophyll cycle pigments (Figure 3). The drop of NPQ shown after HL illumination for $24 \mathrm{~h}$ in WT leaves may be due to the photo-oxidation of PSII, and NPQ could be recovered slowly after the repair of damaged photosystems.

Photochemical protection mechanisms were also activated after $24 \mathrm{~h}$ of HL illumination in WT plants as shown by the changes in ETR (Figure 4A), but not in npq4-1 mutants. When plants were exposed to high light intensity, the size of the electron sink limits photosynthesis. When the electron sinks become saturated, there is an over accumulation of electrons in the photosynthetic electron transport system as observed by the reduction in PQ pool size [27]. When the value of $\mathrm{qL}$ of chlorophyll fluorescence that reflects the reduction of $\mathrm{PQ}$ was measured, qL also significantly decreased during HL illumination in both WT and npq4-1, 
but the recovery in qL was observed only in WT plants, and not in npq4-1 mutants (Figure 5). The long-term HL acclimation processes includes the accumulation of plastoquinone [2], which can quench ${ }^{1} \mathrm{O}_{2}$ and inhibit oxidation of lipid membranes [48-50]. Under HL stress, a dramatic reduction of total PQ-9 content is reported [2], as we have noticed a significant drop in ETR and qL after HL illumination (Figures 4 and 5). Several papers have also reported the accumulation of PQ-9 as a long-term HL acclimation process [38,49,51,52].

The evidence of transcriptional regulation of $\mathrm{PQ}$ accumulation comes from the results of GSEA of cDNA microarray analyses. Interestingly, two gene sets including G14 and L09 are positively enriched in $3 \mathrm{~h}$ and $24 \mathrm{~h}$ HL-treated WT, not in npq4-1 mutants. The genes SPS2 and VTE1 in the G14 gene set are involved in PQ and tocopherol biosynthesis. These genes related to PQ biosynthesis enzymes were upregulated during HL treatment in WT, whereas these genes were not upregulated in npq4-1 mutants (Figure 9A). These results suggest the possibility that the $n p q 4-1$ mutation affects the synthesis of PQ at the transcriptional level during HL acclimation. The function of PQ goes beyond its traditional roles as photosynthetic electron carriers between PSII and PSI and redox signals regulating cellular activities $[45,46]$. Longer-term acclimation to HL was associated with a marked rise in the PQ-9 levels which is followed by the recovery of PSII activity.

In this study, our results also suggest that long-term HL acclimation processes include the recovery of PSII activity with an associated increase in ETR and qL. The increase in ETR and $\mathrm{qL}$ is accompanied by the rise in the expression of genes involved in PQ biosynthesis. In addition, we could observe other processes known to be involved during HL acclimation including the regulation in ROS homeostasis and a reduction in light harvesting antenna size. However, npq4-1 mutants failed to exhibit most of these acclimation processes, especially the expression of genes involved in PQ. Signals that initiate HL acclimation include ROS accumulation, which triggers the expression of PQ biosynthesis genes, such as SPS and $V T E 1$ [2,22]. Because the redox state of the PQ pool affects almost all aspects of the photosynthesis including gene expression, the failure of transcription induction of PQ biosynthesis genes in npq4-1 mutants may interfere with the light stress acclimation processes including antenna size reduction. Upstream signals for the start of the HL acclimation processes may not be properly triggered in the PsbS-deficient npq4-1 mutants.

\section{Materials and Methods}

\subsection{Plant Materials, Growth and HL Treatment Conditions}

Arabidopsis thaliana WT (ecotype Col 0) and npq4-1 mutant plants were grown in soil in a growth chamber with a $16 \mathrm{~h}$ photoperiod at a photosynthetic photon flux density (PPFD) of $70 \mu \mathrm{mol}$ photons $\mathrm{m}^{-2} \mathrm{~s}^{-1}$ with a day/night temperature cycle of $23 / 18{ }^{\circ} \mathrm{C}$. For HL acclimation, 4 to 5-week-old plants were treated with HL at a PPFD of $700 \mu \mathrm{mol}$ photons $\mathrm{m}^{-2} \mathrm{~s}^{-1}$ at $19{ }^{\circ} \mathrm{C}$ on the surface of adaxial side of the leaf.

\subsection{Chlorophyll Fluorescence}

Chlorophyll fluorescence was measured using a PAM-2000 portable chlorophyll fluorometer (PAM2000, Walz, Effeltrich, Germany). The minimum fluorescence at open PSII centers in the dark-adapted state (Fo) was excited by a weak measuring light (wavelength $650 \mathrm{~nm}$ ) at a PPFD of $0.05-0.1 \mu \mathrm{mol}$ photons $\mathrm{m}^{-2} \mathrm{~s}^{-1}$. A saturating pulse of white light with PPFD of $3000 \mu \mathrm{mol}$ photons $\mathrm{m}^{-2} \mathrm{~s}^{-1}$ for $800 \mathrm{msec}$ was applied to determine the maximum fluorescence at closed PSII centers in the dark-adapted state (Fm) and the maximum fluorescence at closed PSII centers in the actinic light (AL)-adapted state $\left(\mathrm{Fm}^{\prime}\right)$. The photochemical efficiency of PSII $(\mathrm{Fv} / \mathrm{Fm})$ was calculated using the equation, $\mathrm{Fv} / \mathrm{Fm}=(\mathrm{Fm}-\mathrm{Fo}) / \mathrm{Fm}$. ETR was computed as previously described as: $\mathrm{ETR}=\left(\Delta \mathrm{F} / \mathrm{Fm}^{\prime}\right) \times \mathrm{PAR} \times 0.5 \times 0.84\left(\Delta \mathrm{F}=\left(\mathrm{Fm}^{\prime}-\mathrm{Ft}\right)\right)$ assuming equal distribution of excitation between PSI and PSII [53]. The parameter qL was determined as described previously $[27,54]$. 


\subsection{Thylakoid Membrane Isolation}

Thylakoid membranes were prepared according to the method described in [55] with some modifications. Detached leaves were ground with a glass homogenizer in ice-cold grinding buffer (50 mM HEPES, pH 7.6, 0.3 M sorbitol, $10 \mathrm{mM} \mathrm{NaCl}, 5 \mathrm{mM} \mathrm{MgCl}$ ). The homogenate was filtered through two layers of Miracloth (Merck, Darmstadt, Germany) and centrifuged at 20,000 $\times g$ in a microcentrifuge (Micro17R, Hanil, Daejeon, Korea) for $7 \mathrm{~min}$. The pellet was then washed twice and resuspended in resuspending buffer $(50 \mathrm{mM}$ HEPES, pH 7.6, 0.1 M sorbitol, $10 \mathrm{mM} \mathrm{NaCl}, 5 \mathrm{mM} \mathrm{MgCl} 2$ ). The suspension was kept on ice in the dark until use after chlorophyll concentrations were measured according to [56].

\subsection{Measurement of Photosynthetic Pigments by High Performance Liquid Chromatography}

Photosynthetic pigments were analyzed according to the method of Gilmore and Yamamoto [57]. Briefly, leaf segments from one month old plants grown in a greenhouse under a $500 \mu \mathrm{mol}$ photons $\mathrm{m}^{-2} \mathrm{~s}^{-1}$ light intensity were collected. The fresh weight of each sample was recorded before dark-adaptation for $3 \mathrm{~h}$. Dark-adapted leaf discs were used as control samples, whereas HL illumination of pre-dark-adapted leaf discs was for $3 \mathrm{~h}$ at $2000 \mu \mathrm{mol}$ photons $\mathrm{m}^{-2} \mathrm{~s}^{-1}$. Dark-adapted and HL illuminated samples were immediately frozen in liquid nitrogen and stored at $-80^{\circ} \mathrm{C}$ until use for pigment extraction. To extract pigments, frozen leaf segments were ground with a Mixer-Mill (Qiagen, Hilden, Germany). The resulting leaf powder was gently agitated in ice-cold acetone for $1 \mathrm{~h}$. To minimize pigment degradation, extraction was performed in darkness at $4{ }^{\circ} \mathrm{C}$. Cell debris was removed by centrifugation twice at $19,000 \times g$ for $10 \mathrm{~min}$ at $4{ }^{\circ} \mathrm{C}$. Extracts were filtered through a $0.2-\mathrm{mm}$ syringe filter and pigments were separated using an HPLC system (Agilent, Santa Clara, CA, USA) equipped with Spherisorb ODS-1 columns (Altech, Nicholasville, KY, USA). The pigment concentration was estimated by using the conversion factors for peak areas (in nmol) that were previously calculated for this solvent mixture [57].

\subsection{Histochemical Staining of Superoxide and Hydrogen Peroxide}

Histochemical staining for ROS production was conducted as previously described [58-60], with some modifications. For superoxide determinations, leaf samples were immersed in $6 \mathrm{mM}$ NBT solution containing $50 \mathrm{mM}$ sodium phosphate ( $\mathrm{pH}$ 7.5) for $12 \mathrm{~h}$ in the dark. To detect hydrogen peroxide, detached leaves were immersed in $5 \mathrm{mM}$ DAB solution containing $10 \mathrm{mM}$ MES ( $\mathrm{pH}$ 3.8) for $12 \mathrm{~h}$ under darkness. After light treatment for $2 \mathrm{~h}$, leaves were then decolorized by immersing them in $70 \%$ ethanol overnight to thoroughly remove the chlorophyll. The cleared leaves were preserved in 50\% ethanol.

\subsection{Fluorometric Detection of Singlet Oxygen}

For the detection of singlet oxygen, leaves were vacuum infiltrated with $200 \mu \mathrm{M} \mathrm{SOSG}$ (Thermo Fisher Scientific, Waltham, MA, USA) in $50 \mathrm{mM}$ phosphate buffer, $\mathrm{pH}$ 7.5. While illuminated with light, the SOSG fluorescence emission was measured at $530 \mathrm{~nm}$ with excitation at $480 \mathrm{~nm}$ using F4500 fluorescence spectrophotometer (Hitachi, Toyoto, Japan).

\subsection{RNA Isolation and Purification}

For microarray experiments, WT and npq4-1 mutants were grown under continuous light for 3 weeks at a light intensity of $70 \mu \mathrm{mol}$ photons $\mathrm{m}^{-2} \mathrm{~s}^{-1}$ at $23^{\circ} \mathrm{C}$ to avoid the effect of circadian rhythm on gene expression. Total RNA was isolated using RNeasy Plant Mini Kit (Qiagen, Hilden, Germany), following the manufacturer's instructions. Briefly, the leaf samples of high-light-treated plants were homogenized in the presence of liquid nitrogen and were lysed in a buffer containing guanidine isothiocyanate. The lysed samples were placed in the RNeasy column and washed with an ethanol-containing buffer. Total RNA was eluted with RNase-free water. For ethanol precipitation, $1 \mathrm{~mL}$ of $95 \%$ ethanol and one-tenth volume of $3 \mathrm{M} \mathrm{NaOAc}$, pH 5.2 were added and the total RNA sample was held at $-80{ }^{\circ} \mathrm{C}$ for $20 \mathrm{~min}$. After centrifuging at $12,000 \times \mathrm{g}$ for $15 \mathrm{~min}$ at $4{ }^{\circ} \mathrm{C}$, the entire RNA pellet was washed with $1 \mathrm{~mL}$ of $70 \%$ ethanol and centrifuged at $12,000 \times \mathrm{g}$ for $5 \mathrm{~min}$ at $4{ }^{\circ} \mathrm{C}$. 
The pellet was dissolved in RNase-free water. The concentration and purity of this isolated total RNA were determined by measuring absorbances at $260 \mathrm{~nm}$ and $280 \mathrm{~nm}$.

\subsection{Microarray Experiment, Image Acquisition, Data Acquisition and Normalization}

Total RNA ( $5 \mathrm{~g}$ ) of leaf samples of $A$. thaliana (Col-0) after treatment of HL at $700 \mu \mathrm{mol}$ photons $\mathrm{m}^{-2} \mathrm{~s}^{-1}$ for 0,3 and $24 \mathrm{~h}$. were reverse-transcribed using reverse transcription (RT) primer tagged with either Cy3-3DNA or Cy5-3DNA capture sequence of Array 900 MPX Expression Array Detection Kits (Genisphere, Hatfield, PA, USA). The synthesized cDNA including capture sequence were fluorescently labeled by Cy3-3DNA or Cy5-3DNA based on the sequence complementary to the 3DNA capture reagent, which contained an average of 900 fluorescent dyes. The labeled cDNA was hybridized on an Operon Arabidopsis Version 3.0 microarray which consists of synthetic 70-mer oligonucleotides on aminosilane-coated slides by the David Galbraith Lab, University of Arizona. The hybridization and washing procedures were performed according to the Genisphere technical protocol. After washing, the slides were immediately scanned using an ArrayWoRx (Applied Precision, Issaquah, WA, USA). To maximize the camera's dynamic range without saturation and to normalize the two channels for signal intensity, the exposure setting was adjusted so that the intensity level of the brightest spot on a slide was 80 to $90 \%$. Experiments were performed with three replicates, which generally used the same material except for the dye labels, which were reversed between duplicate samples for each microarray. Intensity values were quantified from the pairs of TIFF image file from each channel using version 5.6 ImaGene software (BioDiscovery, El Segundo, CA, USA). Analyses were using the version 4.1 GeneSight software package (BioDiscovery, El Segundo, CA, USA). For each slide, the local background was subtracted from the signal intensity and the minimum intensity was raised to 20 by using the 'floor' function. The mean intensity for each element was normalized by the locally weighted scatterplot smoothing (LOWESS) method in GeneSight software.

\subsection{GSEA Analysis Using Chloroplast-Specific Coexpression Gene Set Database}

The GSEA was performed using version 2.0.7 of the GSEA-P software downloaded from GSEA website (http:/ / www.broadinstitute.org/gsea/, accessed on 12 December 2015) [23]. To calculate the significance of the enrichment score (ES), class labels were randomly permuted, and ES were recalculated 1000 times. In this study, the cutoff for significance of ES was defined as the score according to $p$ value of 0.05 and FDR value of 0.25 . A statistically significant value for the gene sets represented by less than 10 genes was defined as $p$ value of 0.1 since a small population size has a negative influence on statistical significance. GSEA evaluated a query microarray data set by using chloroplast-specific co-expression gene set (CC gene set) database.

\subsection{Gene Expression Analysis}

Total RNAs were extracted using TRIzol reagent and reverse-transcribed into cDNAs using the PrimeScript RT reagent kit (TaKaRa, Tokyo, Japan). RT-qPCR was performed using KAPA SYBR FAST qPCR master mix (Kapa Biosystems, Wilmington, MA, USA) with gene-specific primers on a LightCycler 480 system (Roche, Bâle, Switzerland) according to the manufacturer's protocol. For transcript normalization, Actin1 was used as a reference gene. Data were analyzed using LC480Conversion and LinRegPCR software (Heart Failure Research Center).

\subsection{Statistical Analysis}

Statistical analyses were performed using GraphPad Prism (v. 8.0). Nonlinear regression analysis was performed by least square methods. Significant differences between experimental groups were analyzed by one-way ANOVA with Fisher's LSD test or Student's $t$-test, respectively. Detailed information about statistical analysis is described in the Figure legends. Statistical significance was set at $p<0.05$. All experiments were repeated three to five times with similar results. 


\section{Conclusions}

Plant leaves dissipate excessive light as heat by NPQ. A major part of NPQ, $\mathrm{qE}$, has been studied extensively as a short-term protection mechanism against photoinhibition. However, long-term high light acclimation processes are poorly understood. In this study, it was demonstrated that a $\mathrm{qE}$ deficient mutant, $n p q 4-1$ lacking PsbS protein, failed to acclimate well to long-term HL treatment. In WT plants, photosynthesis-related parameters recovered well during long-term $\mathrm{HL}$, while this was not the case for npq4-1 mutants. LHCII antenna size reduction and ROS homeostasis, which occurred during the HL acclimation process in WT plants, were impaired in npq4-1 mutants. This was associated with a reduction in the expression of $\mathrm{PQ}$ biosynthesis genes in $n p q 4-1$ mutants during HL treatment. Taken together, it was found that NPQ, which was considered important for short term-HL acclimation, is also an important mechanism for long-term HL acclimation processes, as is the expression of PQ biosynthesis genes.

Supplementary Materials: The following supporting information can be downloaded at: https: //www.mdpi.com/article/10.3390/ijms23052695/s1.

Author Contributions: Conceptualization, H.U.K., D.-H.L. and C.-H.L.; performed overall experiments, Y.N.Y., I.S.Z. and E.-H.K.; microarray experiments and data analysis, Y.N.Y., T.T.L.L. and J.-H.H.; writing - original draft preparation, Y.N.Y., J.-H.H. and E.-H.K.; writing-review and editing, I.S.Z., H.U.K., J.S.J., D.-H.L. and C.-H.L.; supervision and funding acquisition, C.-H.L. All authors have read and agreed to the published version of the manuscript.

Funding: This study was supported by Basic Science Research Program through the National Research Foundation of Korea (NRF) funded by the Ministry of Education (NRF-2020R111A3069080). The work of J.-S.J. was funded by National Research Foundation (2020R1A2C2012976).

Conflicts of Interest: The authors declare no conflict of interest. The funders had no role in the design of the study; in the collection, analyses, or interpretation of data; in the writing of the manuscript, or in the decision to publish the results.

\section{References}

1. Bassi, R.; Dall'Osto, L. Dissipation of Light Energy Absorbed in Excess: The Molecular Mechanisms. Annu. Rev. Plant Biol. 2021, 72, 47-76. [CrossRef] [PubMed]

2. Ksas, B.; Becuwe, N.; Chevalier, A.; Havaux, M. Plant tolerance to excess light energy and photooxidative damage relies on plastoquinone biosynthesis. Sci. Rep. 2015, 5, 10919. [CrossRef] [PubMed]

3. Li, X.P.; Phippard, A.; Pasari, J.; Niyogi, K.K. Structure-function analysis of photosystem II subunit S (PsbS) in vivo. Funct. Plant Biol. 2002, 29, 1131-1139. [CrossRef]

4. Zulfugarov, I.S.; Ham, O.K.; Mishra, S.R.; Kim, J.Y.; Nath, K.; Koo, H.Y.; Kim, H.S.; Moon, Y.H.; An, G.; Lee, C.H. Dependence of reaction center-type energy-dependent quenching on photosystem II antenna size. Biochim. Biophys. Acta 2007, 1767, 773-780. [CrossRef]

5. Zulfugarov, I.S.; Tovuu, A.; Eu, Y.-J.; Dogsom, B.; Poudyal, R.S.; Nath, K.; Hall, M.; Banerjee, M.; Yoon, U.C.; Moon, Y.-H. Production of superoxide from Photosystem II in a rice (Oryza sativaL.) mutant lacking PsbS. BMC Plant Biol. 2014, 14, 242. [CrossRef]

6. Zulfugarov, I.S.; Wu, G.; Tovuu, A.; Lee, C.H. Effect of oxygen on the non-photochemical quenching of vascular plants and potential oxygen deficiency in the stroma of PsbS-knock-out rice. Plant Sci. 2019, 286, 1-6. [CrossRef] [PubMed]

7. Li, X.P.; Bjorkman, O.; Shih, C.; Grossman, A.R.; Rosenquist, M.; Jansson, S.; Niyogi, K.K. A pigment-binding protein essential for regulation of photosynthetic light harvesting. Nature 2000, 403, 391-395. [CrossRef]

8. Brooks, M.D.; Jansson, S.; Niyogi, K.K. PsbS-dependent non-photochemical quenching. In Non-Photochemical Quenching and Energy Dissipation in Plants, Algae and Cyanobacteria; Springer: Berlin/Heidelberg, Germany, 2014; pp. 297-314.

9. Apel, K.; Hirt, H. Reactive oxygen species: Metabolism, oxidative stress, and signal transduction. Annu. Rev. Plant Biol. 2004, 55, 373-399. [CrossRef]

10. Huang, J.; Zhao, X.; Chory, J. The Arabidopsis Transcriptome Responds Specifically and Dynamically to High Light Stress. Cell Rep. 2019, 29, 4186-4199. [CrossRef]

11. Rantala, M.; Tikkanen, M.; Aro, E.M. Proteomic characterization of hierarchical megacomplex formation in Arabidopsis thylakoid membrane. Plant J. 2017, 92, 951-962. [CrossRef]

12. Schwarz, E.M.; Tietz, S.; Froehlich, J.E. Photosystem I-LHCII megacomplexes respond to high light and aging in plants. Photosynth. Res. 2018, 136, 107-124. [CrossRef] [PubMed] 
13. Tikkanen, M.; Rantala, S.; Grieco, M.; Aro, E.-M. Comparative analysis of mutant plants impaired in the main regulatory mechanisms of photosynthetic light reactions-From biophysical measurements to molecular mechanisms. Plant Physiol. Biochem. 2017, 112, 290-301. [CrossRef] [PubMed]

14. Kirchhoff, H. Structural changes of the thylakoid membrane network induced by high light stress in plant chloroplasts. Philos. Trans. R. Soc. Lond. B Biol. Sci. 2014, 369, 20130225. [CrossRef] [PubMed]

15. Zulfugarov, I.S.; Tovuu, A.; Kim, J.-H.; Lee, C.-H. Detection of reactive oxygen species in higher plants. J. Plant Biol. 2011, $54,351$. [CrossRef]

16. Pinnola, A.; Bassi, R. Molecular mechanisms involved in plant photoprotection. Biochem. Soc. Trans. 2018, 46, 467-482. [CrossRef] [PubMed]

17. Osmond, C. What is photoinhibition? Some insights from comparisons of shade and sun plants. Photoinhib. Photosynth. Mol. Mech. Field 1994, 1-24.

18. Melis, A.; Neidhardt, J.; Benemann, J.R. Dunaliella salina (Chlorophyta) with small chlorophyll antenna sizes exhibit higher photosynthetic productivities and photon use efficiencies than normally pigmented cells. J. Appl. Phycol. 1998, 10, 515-525. [CrossRef]

19. Baroli, I.; Melis, A. Photoinhibitory damage is modulated by the rate of photosynthesis and by the photosystem II light-harvesting chlorophyll antenna size. Planta 1998, 205, 288-296. [CrossRef]

20. Roach, T.; Krieger-Liszkay, A. The role of the PsbS protein in the protection of photosystems I and II against high light in Arabidopsis thaliana. Biochim. Biophys. Acta 2012, 1817, 2158-2165. [CrossRef]

21. Amesz, J. The function of plastoquinone in photosynthetic electron transport. Biochim. Biophys. Acta BBA Rev. Bioenerg. 1973, 301, 35-51. [CrossRef]

22. Ksas, B.; Légeret, B.; Ferretti, U.; Chevalier, A.; Pospíšil, P.; Alric, J.; Havaux, M. The plastoquinone pool outside the thylakoid membrane serves in plant photoprotection as a reservoir of singlet oxygen scavengers. Plant Cell Environ. 2018, 41, 2277-2287. [CrossRef] [PubMed]

23. Subramanian, A.; Tamayo, P.; Mootha, V.K.; Mukherjee, S.; Ebert, B.L.; Gillette, M.A.; Paulovich, A.; Pomeroy, S.L.; Golub, T.R.; Lander, E.S. Gene set enrichment analysis: A knowledge-based approach for interpreting genome-wide expression profiles. Proc. Natl. Acad. Sci. USA 2005, 102, 15545-15550. [CrossRef] [PubMed]

24. Byun, Y.J.; Koo, M.Y.; Joo, H.J.; Ha-Lee, Y.M.; Lee, D.H. Comparative analysis of gene expression under cold acclimation, deacclimation and reacclimation in Arabidopsis. Physiol. Plant. 2014, 152, 256-274. [CrossRef] [PubMed]

25. Niyogi, K.K.; Grossman, A.R.; Björkman, O. Arabidopsis mutants define a central role for the xanthophyll cycle in the regulation of photosynthetic energy conversion. Plant Cell 1998, 10, 1121-1134. [CrossRef] [PubMed]

26. Zulfugarov, I.S.; Tovuu, A.; Dogsom, B.; Lee, C.Y.; Lee, C.-H. PsbS-specific zeaxanthin-independent changes in fluorescence emission spectrum as a signature of energy-dependent non-photochemical quenching in higher plants. Photochem. Photobiol. Sci. 2010, 9, 697-703. [CrossRef]

27. Miyake, C.; Amako, K.; Shiraishi, N.; Sugimoto, T. Acclimation of tobacco leaves to high light intensity drives the plastoquinone oxidation system-relationship among the fraction of open PSII centers, non-photochemical quenching of Chl fluorescence and the maximum quantum yield of PSII in the dark. Plant Cell Physiol. 2009, 50, 730-743. [CrossRef]

28. Fridovich, I. Superoxide anion radical (O-2), superoxide dismutases, and related matters. J. Biol. Chem. 1997, $272,18515-18517$. [CrossRef]

29. Telfer, A.; Dhami, S.; Bishop, S.M.; Phillips, D.; Barber, J. beta-Carotene quenches singlet oxygen formed by isolated photosystem II reaction centers. Biochemistry 1994, 33, 14469-14474. [CrossRef]

30. Dall'Osto, L.; Cazzaniga, S.; Havaux, M.; Bassi, R. Enhanced photoprotection by protein-bound vs free xanthophyll pools: A comparative analysis of chlorophyll b and xanthophyll biosynthesis mutants. Mol. Plant 2010, 3, 576-593. [CrossRef]

31. de Bianchi, S.; Betterle, N.; Kouril, R.; Cazzaniga, S.; Boekema, E.; Bassi, R.; Dall'Osto, L. Arabidopsis mutants deleted in the light-harvesting protein Lhcb4 have a disrupted photosystem II macrostructure and are defective in photoprotection. Plant Cell 2011, 23, 2659-2679. [CrossRef]

32. Björkman, O. Comparative studies on photosynthesis in higher plants. In Photophysiology; Elsevier: Amsterdam, The Netherlands, 1973; pp. 1-63.

33. Anderson, J.; Barrett, J. Light-harvesting pigment-protein complexes of algae. In Encyclopedia of Plant Physiology; Staehelin, L.A., Arntzen, C.J., Eds.; Springer: Berlin/Heidelberg, Germany, 1986; Volume 19, pp. 269-285.

34. Perrine, Z.; Negi, S.; Sayre, R.T. Optimization of photosynthetic light energy utilization by microalgae. Algal Res. 2012, 1, 134-142. [CrossRef]

35. Melis, A.; Harvey, G. Regulation of photosystem stoichiometry, chlorophyll a and chlorophyll b content and relation to chloroplast ultrastructure. Biochim. Biophys. Acta BBA Bioenerg. 1981, 637, 138-145. [CrossRef]

36. Leong, T.Y.; Anderson, J.M. Adaptation of the thylakoid membranes of pea chloroplasts to light intensities. I. Study on the distribution of chlorophyll-protein complexes. Photosynth. Res. 1984, 5, 105-115. [CrossRef] [PubMed]

37. Lindahl, M.; Yang, D.H.; Andersson, B. Regulatory proteolysis of the major light-harvesting chlorophyll a/b protein of photosystem II by a light-induced membrane-associated enzymic system. Eur. J. Biochem. 1995, 231, 503-509. [CrossRef]

38. Havaux, M.; Eymery, F.; Porfirova, S.; Rey, P.; Dormann, P. Vitamin E protects against photoinhibition and photooxidative stress in Arabidopsis thaliana. Plant Cell 2005, 17, 3451-3469. [CrossRef] 
39. Powles, S.B. Photoinhibition of photosynthesis induced by visible light. Annu. Rev. Plant Physiol. 1984, 35, 15-44. [CrossRef]

40. Osmond, B.; Förster, B. Photoinhibition: Then and now. In Photoprotection, Photoinhibition, Gene Regulation, and Environment; Springer: Berlin/Heidelberg, Germany, 2008; pp. 11-22.

41. Chow, W.S.; Melis, A.; Anderson, J.M. Adjustments of photosystem stoichiometry in chloroplasts improve the quantum efficiency of photosynthesis. Proc. Natl. Acad. Sci. USA 1990, 87, 7502-7506. [CrossRef]

42. Bailey, S.; Walters, R.G.; Jansson, S.; Horton, P. Acclimation of Arabidopsis thaliana to the light environment: The existence of separate low light and high light responses. Planta 2001, 213, 794-801. [CrossRef]

43. Kouřil, R.; Wientjes, E.; Bultema, J.B.; Croce, R.; Boekema, E.J. High-light vs. low-light: Effect of light acclimation on photosystem II composition and organization in Arabidopsis thaliana. Biochim. Biophys. Acta BBA Bioenerg. 2013, 1827, 411-419. [CrossRef]

44. Wientjes, E.; van Amerongen, H.; Croce, R. LHCII is an antenna of both photosystems after long-term acclimation. Biochim. Biophys. Acta BBA Bioenerg. 2013, 1827, 420-426. [CrossRef]

45. Yang, D.H.; Webster, J.; Adam, Z.; Lindahl, M.; Andersson, B. Induction of acclimative proteolysis of the light-harvesting chlorophyll a/b protein of photosystem II in response to elevated light intensities. Plant Physiol. 1998, 118, 827-834. [CrossRef] [PubMed]

46. Horie, Y.; Ito, H.; Kusaba, M.; Tanaka, R.; Tanaka, A. Participation of chlorophyll b reductase in the initial step of the degradation of light-harvesting chlorophyll a/b-protein complexes in Arabidopsis. J. Biol. Chem. 2009, 284, 17449-17456. [CrossRef]

47. Li, Z.; Wakao, S.; Fischer, B.B.; Niyogi, K.K. Sensing and responding to excess light. Annu. Rev. Plant Biol. 2009, 60, 239-260. [CrossRef] [PubMed]

48. Kruk, J.; Szymanska, R. Singlet oxygen and non-photochemical quenching contribute to oxidation of the plastoquinone-pool under high light stress in Arabidopsis. Biochim. Biophys. Acta 2012, 1817, 705-710. [CrossRef] [PubMed]

49. Kruk, J.; Trebst, A. Plastoquinol as a singlet oxygen scavenger in photosystem II. Biochim. Biophys. Acta 2008, 1777, 154-162. [CrossRef]

50. Gruszka, J.; Pawlak, A.; Kruk, J. Tocochromanols, plastoquinol, and other biological prenyllipids as singlet oxygen quenchersdetermination of singlet oxygen quenching rate constants and oxidation products. Free Radical Bio. Med. 2008, 45, 920-928. [CrossRef]

51. Szymańska, R.; Kruk, J. Plastoquinol is the main prenyllipid synthesized during acclimation to high light conditions in Arabidopsis and is converted to plastochromanol by tocopherol cyclase. Plant Cell Physiol. 2010, 51, 537-545. [CrossRef]

52. Lichtenthaler, H.K. Biosynthesis, accumulation and emission of carotenoids, alpha-tocopherol, plastoquinone, and isoprene in leaves under high photosynthetic irradiance. Photosynth. Res. 2007, 92, 163-179. [CrossRef]

53. Kim, J.-H.; Kim, S.-J.; Cho, S.H.; Chow, W.S.; Lee, C.-H. Photosystem I acceptor side limitation is a prerequisite for the reversible decrease in the maximum extent of P700 oxidation after short-term chilling in the light in four plant species with different chilling sensitivities. Physiol. Plantarum 2005, 123, 100-107. [CrossRef]

54. Kramer, D.M.; Avenson, T.J.; Edwards, G.E. Dynamic flexibility in the light reactions of photosynthesis governed by both electron and proton transfer reactions. Trends Plant Sci. 2004, 9, 349-357. [CrossRef]

55. Aro, E.M.; McCaffery, S.; Anderson, J.M. Photoinhibition and D1 Protein Degradation in Peas Acclimated to Different Growth Irradiances. Plant Physiol. 1993, 103, 835-843. [CrossRef]

56. Porra, R.J.; Thompson, W.A.; Kriedemann, P.E. Determination of accurate extinction coefficients and simultaneous equations for assaying chlorophylls a and b extracted with four different solvents: Verification of the concentration of chlorophyll standards by atomic absorption spectroscopy. Biochim. Biophys. Acta BBA Bioenerg. 1989, 975, 384-394. [CrossRef]

57. Gilmore, A.M.; Yamamoto, H.Y. Resolution of lutein and zeaxanthin using a non-endcapped, lightly carbon-loaded C18 highperformance liquid chromatographic column. J. Chromatogr. 1991, 543, 137-145. [CrossRef]

58. Fryer, M.J.; Oxborough, K.; Mullineaux, P.M.; Baker, N.R. Imaging of photo-oxidative stress responses in leaves. J. Exp. Bot. 2002, 53, 1249-1254. [CrossRef] [PubMed]

59. Kariola, T.; Brader, G.; Li, J.; Palva, E.T. Chlorophyllase 1, a damage control enzyme, affects the balance between defense pathways in plants. Plant Cell 2005, 17, 282-294. [CrossRef]

60. Mahalingam, R.; Jambunathan, N.; Gunjan, S.K.; Faustin, E.; Weng, H.; Ayoubi, P. Analysis of oxidative signalling induced by ozone in Arabidopsis thaliana. Plant Cell Environ. 2006, 29, 1357-1371. [CrossRef] 